\title{
Design editorial e a preservação das memórias de uma família através de um livro de receitas
}

\section{Editorial design and preservation of a family's memories through a cookbook}

\author{
Natália Marroni Marques ${ }^{[1]}$, \\ Ana da Rosa Bandeira ${ }^{[2]}$ (orientadora)
}

\begin{abstract}
Resumo: Este artigo tem como objetivo relatar a construção de um livro de receitas como sendo um artefato capaz de cristalizar e evocar memórias vividas em família, além de servir como transmissor de tradições através das gerações. A pesquisa que deu origem ao texto foi elaborada como Trabalho de Conclusão de Curso no curso de Design Gráfico da UFPel e foi pautada no estudo do Design Editorial e seus elementos, além disso destacou-se a memória como formadora da identidade individual capaz de estabelecer vínculos emocionais com objetos que retratam a história familiar. Buscou-se então, como prática projetual, a criação do livro Doce de Vó, o qual reuniu algumas receitas feitas pela avó da autora, materializando esses momentos por meio de fotografias, passo a passo e dicas.

Palavras-chave: Design editorial. Livro de receitas. Memória. Família.
\end{abstract}

[1] Graduação (em andamento) em Design Gráfico, UFPEL. marquesnat@hotmail.com

[2] Doutorado em Comunicação e Informação, UFRGS.

anaband@gmail.com 


\begin{abstract}
This article aims to report on the build-up of a cookbook as an artifact that is able to crystallize and evoke memories lived in a family, as well as to serve as a generational tradition transmitter. The research that originated the text was elaborated as a Course Completion Work in the Graphic Design course of UFPel and was based on the study of Editorial Design and its elements and, beyond that, memory was highlighted as an individual identity shaper capable of establishing emotional links to objects that depict the family history. It was sought, as project practic, the creation of the book Doce de Vó, which assembled some of the recipes made by the author's grandmother, reifying these moments through the medium of photography, step-by-step and tips.
\end{abstract}

Keywords: Editorial Design. Cookbook. Memory. Family.

\title{
INTRODUÇÃO
}

As pessoas são a soma de tudo o que viram e viveram anteriormente. As experiências que tiveram durante suas vidas alteram diretamente suas maneiras de pensar, agir e as forma como indivíduos. Elas residem e são acessadas por meio de suas memórias e, dessa forma, estão diretamente interligadas e se auto-influenciam. Entretanto, a memória se mostra falha no processo de esquecer coisas que até então eram importantes para dar lugar a novas prioridades. Sendo assim, as pessoas recorrem a objetos como suporte de suas memórias (CARDOSO, 2012).

Diante disso, a presente pesquisa pretende relacionar o design e a memória com o objetivo de projetar um livro de receitas para servir como suporte de lembranças compartilhadas em família, registrando e tornando concreto algo que hoje habita apenas as recordações de seus integrantes. A ideia é que desta forma as memórias de família não se percam com o passar dos anos, tendo a chance de seguir vivas por mais tantas outras gerações. Grande parte dessas receitas não possuem um registro escrito e se encontram somente na memória da avó da autora ou em papéis envelhecidos pelo tempo, sendo assim, estão suscetíveis a cair em esquecimento.

Dentre os objetivos específicos que buscou-se alcançar com este trabalho estão a coleta de informações por meio de pesquisa documental, tanto através de fotos e livros antigos da família, quanto com cada um de seus membros, com o intuito de listar as receitas indispensáveis para constar nesse livro. Além disso, procurou-se articular conceitos sobre de- 
sign, culinária e memória, e ainda categorizar os elementos que compõem um livro de receitas. Por fim, preparou-se algumas dessas receitas, para assim poder descrever o passo a passo de forma fiel e tornar esse momento mais do que uma coleta de informações, mas também uma troca de carinho e reconhecimento à pessoa que se dedicou e ainda se dedica a toda a sua família durante sua vida.

Este trabalho parte da problemática de como a relação entre design e memória pode auxiliar no desenvolvimento de um livro de receitas, para que este sirva como suporte na imortalização das memórias de uma família.

Baseando-se nos conceitos apresentados por Gil (2002; 2008), a metodologia utilizada para o desenvolvimento teórico deste trabalho é de uma pesquisa qualitativa de caráter exploratório, pois ela possui a finalidade de proporcionar ao pesquisador uma visão geral, de forma que se crie maior familiaridade sobre o assunto. Assim como neste trabalho, é comum nestes casos que sejam envolvidos como procedimentos técnicos um levantamento bibliográfico e um documental. No levantamento bibliográfico, são utilizados materiais já elaborados anteriormente, como livros e artigos científicos para servirem como embasamento teórico para a pesquisa. Apesar de semelhantes, a principal diferença entre o bibliográfico e o documental, é que no segundo há a apropriação de materiais, os quais ainda não tiveram um tratamento analítico, como por exemplo: cartas pessoais, diários, fotografias e gravações (GIL, 2008). Ambos foram de extrema importância na constituição desta pesquisa. A leitura bibliográfica permitiu que fossem compreendidos conceitos até então desconhecidos, aumentando a bagagem da autora e dando suporte para a justificativa da escolha do tema e o levantamento documental feito junto à família proporcionou a escolha das receitas que compõe a prática projetual desta pesquisa.

Por ser um livro cujo público alvo se restringe à família da autora, a metodologia projetual partiu de momentos compartilhados entre eles. A lista de receitas a serem feitas e suas 
justificativas, os registros dos encontros dessas preparações, as receitas escritas, o passo a passo e as fotografias dos pratos feitos são apresentados na seção do projeto prático.

\section{DESIGN E MEMÓRIA}

Na Grécia Antiga, a memória era considerada uma identidade sobrenatural. A Deusa Mnemosyne era conhecida como a personificação da memória e protetora das Artes e História. Acreditava-se que ela concedia aos artistas o poder de voltar ao passado e gravá-lo perante a eternidade, pois estes, ao registrar em suas obras as fisionomias, gestos, atos e palavras, tornavam-as inesquecíveis. Os historiadores colocavam suas obras sob proteção da Deusa, pedindo que seus feitos memoráveis não fossem perdidos e pudessem servir de exemplo às próximas gerações (CHAUI, 2000).

Atualmente, ao pensar em memória não leva-se mais em conta os conceitos da mitologia grega. Entende-se o termo "memória" como "uma evocação do passado. É a capacidade humana para reter e guardar o tempo que se foi, salvando-o da perda total" (CHAUI, 2000, p.158). Isto é, as pessoas possuem aptidão de armazenar informações, vivências e momentos relevantes que estão no passado e não podem mais voltar, porém conseguem ter acesso a eles através de suas lembranças. Chaui acredita que "guardamos na memória aquilo que possui maior significação ou maior impacto em nossas vidas, mesmo que seja um momento fugaz, curtíssimo e que jamais se repetiu ou se repetirá" (Idem, p. 162). Baseando-se nessa fugacidade, Cardoso (2012, p.74) acrescenta à discussão que "Como o momento atual é passageiro, desmanchando-se numa sucessão de outros momentos, outras vivências, quase tudo que somos e pensamos depende da memória".

Segundo Cardoso (2012) o dito popular "recordar é viver" está equivocado, pois na verdade viver é uma constante recordação de tudo o que foi experienciado e vivenciado até o presente momento. Essas experiências alimentam a memória, a qual consequentemente alimenta as experiências, 
constituindo um ciclo "vicioso" de uma bagagem que cresce de forma ininterrupta. Essa bagagem, tanto de forma direta (vividas pelo indivíduo), quanto emprestada (contada por outrem), altera a sua percepção e a maneira como significam os ocorridos do dia a dia.

Cada pessoa possui um entendimento e interpretação de algo de acordo com sua vivência e isso é o que estabelece sua identidade. Cardoso (2012, p.73) afirma que "a capacidade de lembrar o que já se viveu ou aprendeu e relacionar isso com a situação presente é o mais importante mecanismo de constituição e preservação da identidade de cada um". Porém, “a identidade está em fluxo constante e sujeita a transformações, equivalendo a um somatório de experiências, multiplicadas pelas inclinações e divididas pelas memórias" (Idem, p. 93) e isso se deve ao fato de que o momento atual já não é mais o mesmo do que há um segundo. “A memória é, pois, inseparável do sentimento do tempo ou da percepção/experiência do tempo como algo que escoa ou passa" (CHAUI, 2000, p.159). O tempo se renova a todo instante, dessa forma, quase tudo o que são e pensam é fruto da memória de cada um.

Apesar do ato de lembrar ser uma ação individual, ele é arraigado ao coletivo, pois nunca se está realmente a sós ao se ter uma lembrança, visto que em pensamentos deslocam-se frequentemente de um grupo social a outro. Para Halbwachs (1990), a memória é um fenômeno social, pois cada memória individual é na verdade o ponto de vista de uma memória coletiva. Essa perspectiva se altera de acordo com o papel social adotado pelo indivíduo e pelo grupo de convívio em que está inserido, seja ele a classe social, a escola, a igreja ou a família. Entretanto, essas memórias coletivas precisam ser exercitadas, pois para o autor, ao deixar de conviver com determinado grupo, as memórias relacionadas a eles acabam sendo esquecidas. Por ser o principal grupo de convívio até a vida adulta, a família é o mais importante grupo social para a reconstrução do passado. É ela a materialização da memória coletiva, pois as memórias mesmo que vivenciadas 
por outros membros, tornam-se parte do conjunto e agregam-se a bagagem individual por conta das repetidas vezes em que escuta-se determinadas lembranças (DEMETERCO, 2003; BARROS, 1989).

Entretanto, como aponta Cardoso (2012), a memória é falha e não consegue armazenar informações para depois recuperá-las intactas em um banco de dados assim como acontece nos computadores. Por isso, as pessoas apropriam-se de objetos para servirem de suporte a essas memórias e assim mantê-las vivas. O livro resultante do trabalho de conclusão de curso em que este artigo se baseia, busca então, servir como um artefato que seja a referência de um tempo, onde as pessoas possam encontrar a materialização desse período e trazer à tona as memórias da maneira mais fiel possível.

De acordo com Prown apud Polidori (2014, p. 17) artefato é um "objeto feito ou modificado pelo homem que auxilia o estudo da cultura material de uma sociedade". Para explicar a principal diferença entre um simples objeto e um artefato, Cardoso (2012) acrescenta à discussão:

Uma montanha, uma pedra ou uma árvore são objetos, mas não artefatos. Artefato é um objeto feito pela incidência da ação humana sobre a matéria-prima: em outras palavras, por meio da fabricação. Sua raiz etimológica está no latim arte factus, "feito com arte"; e ela está na origem do termo "artificial", ou seja: tudo aquilo que não é natural (CARDOSO, 2012, p. 47).

Artefatos não são a memória em si, mas sim a cristalização de parte delas em forma de objetos concretizados pelo homem, os quais servem de ponto de partida na retomada dessas lembranças. Eles retratam as relações sociais entre as pessoas e os aspectos culturais que as rodeavam no passado e por meio deles podem ser vistos no presente (LIMA, 2010; 2015).

Segundo Cardoso (2012, p. 76), "os artefatos mais comumente usados em nossa sociedade para preservar e atestar memórias são as fotografias". Barros (1989) explica que isso ocorre porque busca-se por meio delas um modo de confir- 
mar a veracidade dessas lembranças, pois elas cristalizam um acontecimento e carregam consigo emoções e sentimentos. É esperado que aqueles que presenciaram o momento em que a fotografia foi tirada ajudem a decifrar o passado para quem as herdou.

A imagem traz ali presente uma pista para o caminho da memória. Não apenas da memória de vivências passadas, mas de uma memória ancestral. [...] $\mathrm{Na}$ verdade, esta imagem representa a prova ou o testemunho da existência de pessoas, de lugares e de paisagens. [...] Histórias de vida ou trajetórias de família são construídas por· que está disponível a documentação que as confirma (BARROS, 1989, p.39).

Entretanto, não são somente as fotografias que possuem a função de trazer à tona as memórias familiares. Chamados de "mementos" ou "memorabilia", móveis como a cama de madeira trabalhada e a cômoda da sala; objetos como diários, agendas, souvenirs de viagens e outras relíquias são artefatos que estão inseridos no vasto universo de objetos que também carregam em si o simbolismo familiar e podem ser transcritos como bens que contêm e contam uma história (BARROS, 1989; CARDOSO, 2012).

A socióloga Maria Costa (1995) escreve sobre os tesouros domésticos, individuais e familiares. Ao longo da vida acumula-se objetos que podem participar do cotidiano de cada um com maior ou menor frequência ou então servirem apenas de figurantes no cenário da sua existência. Com alguns desses objetos adquire-se uma relação de afeto e eles passam a constituir parte de sua identidade. E esse vínculo não se restringe apenas ao individual. Ao assistir um ente querido adotando um objeto como fonte de devoção, este torna-se um tesouro familiar, pois ao avistá-lo, imediatamente lembra-se do indivíduo, mesmo que ele não esteja mais presente.

Esses objetos acabam constituindo tesouros domésticos, individuais ou familiares. [...] Os acervos domésticos são compostos de objetos significativos para a identidade 
e a memória da família. Alguns podem ter também um alto valor de mercado, como retratos pintados por artistas célebres, joias e mobiliários que, entretanto, do ponto de vista de seu valor simbólico, não são mais valiosos do que a certidão de nascimento de um dos membros da família ou a correspondência do primeiro namorado (COSTA, 1995, p. 38-39).

Costa (1995) segue em seu artigo ao falar sobre a construção dos acervos domésticos. Estes são compostos por objetos marcantes na memória e identidade familiar e permanecem protegidos pelos guardiões, responsáveis ou documentalistas que normalmente são os próprios membros da família. A socióloga acredita que toda casa possui uma "reserva técnica", que podem ser gavetas, baús ou caixas reutilizadas onde são armazenados os objetos que constituem o valor simbólico e o testemunho da história individual ou familiar. Tal coleção passa por uma atualização de tempos em tempos, onde artefatos são adicionados ou retirados, pois no decorrer dos anos podem acabar perdendo seu significado ou até mesmo serem promovidos a objetos expostos pela casa, como fotografias emolduradas sobre os móveis da sala.

Myriam de Barros (1989) em seu artigo sobre Memória e Família, disserta sobre a importância da manutenção da identidade de um grupo social através da memória. No âmbito familiar, esse papel de mediador, geralmente é designado aos avós. Eles são o elo vivo entre as gerações, transmitindo um passado vivido e experienciado pelos seus antecedentes aos seus descendentes. Para ela, a relevância do grupo familiar na reconstrução do passado advém do fato de a família ser, concomitantemente, o objeto das recordações individuais e o espaço em que essas podem ser avivadas.

Ainda no mesmo estudo, Barros (1989), ao realizar entrevistas com avós, percebe a recorrência em que estes citam seus próprios avós como modelos a serem seguidos. Os detalhes e minúcias contadas por eles projetam o perfil do estilo de vida de suas famílias. As lembranças dos entrevistados trazem à tona o valor dos avós como fonte de transmissão de bens simbólicos, 
que para eles representam um valor social e moral. Estes bens não precisam ser necessariamente objetos transferíveis entre gerações, a pesquisadora cita como exemplos suas entrevistadas que foram ensinadas por suas avós a ler, costurar, cozinhar, rezar e a viver. Dessa maneira, essas avós que cumpriram seus papéis de transmissoras, esperam que um pedaço delas sobrevivam em seus netos e que estes carreguem para sempre as marcas que elas deixaram. Entretanto, essa troca de conhecimento não fica restrita somente de avós para netos, Barros (1989, p.36), afirma que "a transmissão de bens simbólicos às gerações seguintes situa a família como o lugar dessa passagem, fazendo de cada descendente o alvo e ao mesmo tempo o veículo da preservação dos valores familiares".

Sendo assim, o objeto impresso que resulta desta pesquisa pretende ser um suporte de memórias responsável pela transmissão de valores simbólicos familiares aprendidos com a avó da autora, a qual adquiriu seus conhecimentos também com sua avó. Esta é uma forma de materializar ensinamentos impalpáveis de forma que se facilitem as futuras transmissões geracionais, além de propagá-los entre os demais familiares.

A seguir são abordados alguns apontamentos iniciais acerca do Design Editorial, para que as intenções projetuais sejam compreendidas e aprofundadas mais adiante na seção em que é apresentada a construção do livro de receitas, objeto desta pesquisa.

\section{O LIVRO E SEUS ELEMENTOS ESTRUTURAIS: ALGUNS APONTAMENTOS}

A forma mais simples de explicar o que é um livro é classificando-o como um objeto transportável composto por um conjunto de páginas que carrega informações e uma capa que protege seu interior. Segundo o Dicionário Michaelis (2017), um livro é "1. Conjunto de folhas de papel, impressas ou manuscritas, coladas ou costuradas num dos lados, cober- 
tas por uma capa". Thaís Sehn em sua pesquisa de conclusão de curso, o define como

um objeto tridimensional, que pode ser levado para qualquer lugar, cuja função principal é armazenar textos, mas ele acaba ensinando sobre diversos assuntos, apresentando mundos novos e alimentando a imaginação de muitas pessoas. [...] O livro pode ser dividido em capa e miolo. A capa envolve o livro, o identifica e protege; o miolo é composto por todas as páginas internas, é onde consta o conteúdo propriamente dito (SEHN, 2009, p.52).

Porém, um livro é muito mais do que simplesmente um conjunto de páginas carregado de informação e coberto por uma capa. Livros tornaram-se produtos de consumo, bens materiais e emocionais, assim como objetos de desejo. $\mathrm{O}$ design do livro precisa ser atrativo para se destacar em meio a tantas outras publicações semelhantes em estantes e prateleiras de livrarias e para gerar o interesse do público.

Richard Hendel (2006, p. 33) faz uma analogia entre designers e arquitetos em seu livro O Design do Livro. Ele afirma que "Os designers estão para os livros assim como os arquitetos estão para os edifícios. [...] Mesmo o detalhe mais aparentemente trivial precisa ser decidido, e são exatamente essas minúcias que tornam bem-sucedido um design". Diante dessa afirmação, percebe-se que para o desenvolvimento do projeto gráfico de um livro é necessário estudar os conceitos que permeiam o design editorial para que um resultado coeso e satisfatório seja atingido.

Para começar o projeto de um livro, Hendel (2006) acredita que a primeira coisa a se pensar é o formato que ele terá. Apesar de ser possível a impressão em qualquer forma, por questões de praticidade e costume, o retângulo vertical é o mais usado. Além disso, para livros reproduzidos em grande escala há outros itens que devem ser levados em consideração, como os custos e a fibra do papel. Ao serem fabricadas, as fibras que compõem uma folha, são alinhadas no mesmo sentido, tornando mais fácil a dobra na direção de um retân- 
gulo vertical, por isso, para projetar um livro na horizontal ou em formatos específicos, é preciso utilizar papéis especiais, tornando o produto final mais caro (HENDEL, 2006). Neste caso, por ser um livro que será impresso em baixa tiragem e em gráfica expressa, não foi levado em conta os custos totais de impressão/tiragem, uma vez que ele será produzido por demanda, muito provavelmente, a partir de cópias individuais impressas em gráficas expressas, a laser.

Após a definição do formato, é preciso determinar as divisões internas da página. Essa construção é conhecida como grid ou grade e funciona como guias que auxiliam no trabalho do designer de resolver problemas e organizar texto, figuras, símbolos, títulos e tabelas. Essa organização torna a leitura mais agradável, pois constrói uma identidade que gera consistência e coerência visual ao projeto, fazendo com o que o leitor percorra as páginas com agilidade e constância. Mesmo que a escolha da grade seja critério do designer, existem modelos pré-estabelecidos (Figura 1) que auxiliam no desenvolvimento desse tipo de estruturação (SAMARA, 2007; HASLAM, 2010).

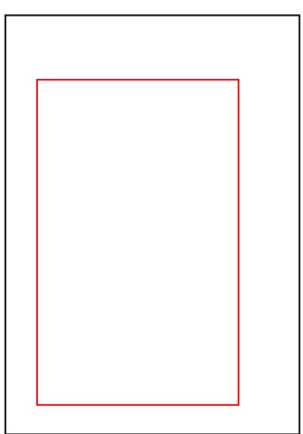

Grid retangular

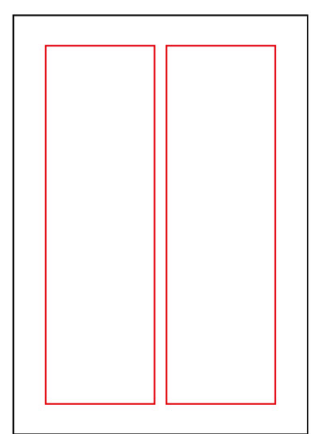

Grid de colunas

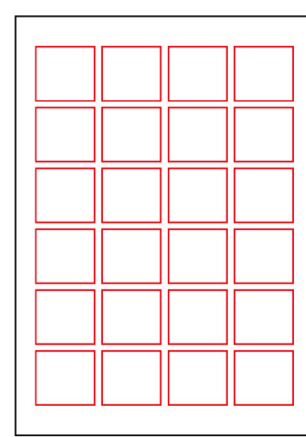

Grid modular

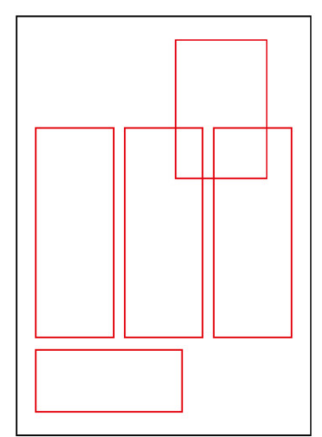

Grid hierárquico
Figura 1: Tipos de grid. Fonte: Adaptado de Samara, 2007.

Para Samara (2007), o grid retangular é a estrutura mais simples, a qual ocupa grande parte da página e tem como objetivo acomodar textos corridos. O grid de colunas torna 
a informação mais dinâmica e flexível, podendo acomodar texto corrido, imagens, legendas e pequenos textos de forma harmônica em uma página. Similar ao anterior, no grid modular também há colunas, porém estas são cortadas por linhas horizontais que as subdividem em quadrados ou retângulos, criando os chamados módulos. Esse modelo é usado para projetos de maior complexidade e que exigem maior controle da maneira em que as informações são distribuídas na página. Já o grid hierárquico é utilizado quando as exigências da informação de determinado projeto não se encaixam em nenhuma outra categoria já citada. Dessa forma, o grid é criado para que se adapte a tal necessidade, baseando-se na disposição e alinhamento intuitivo das informações.

Depois de definido o formato e construído o grid, é hora de escolher as tipografias que irão dar forma ao texto nas páginas do livro. Lupton (2006, p.42) as classifica em três principais categorias (Figura 2). As letras humanistas são inspiradas em características da caligrafia clássica e ao movimento da mão, podendo ter ou não serifa. Neste primeiro caso, notamos as serifas anguladas e os traços curvos afinados. Já as letras transicionais são mais abstratas e menos orgânicas e possuem um eixo mais vertical do que o anterior. Também podem ter ou não serifa, porém neste tipo, elas são mais "afiadas" do que a anterior. A terceira categoria é a moderna, a qual é radicalmente mais abstrata que as anteriores, pois apresentam um grande contraste entre os traços finos e grossos, possui um eixo vertical e as serifas são finas e retas. O'Grady (2008, p.124) acrescenta ainda outra categoria de classificação de tipos, chamada de display (Figura 3), essa reúne tipografias decorativas, como as que imitam a caligrafia à mão ou fontes temáticas. Geralmente essas são aplicadas em títulos ou elementos específicos, pois se usadas em demasia, afetam a legibilidade do texto. 


\section{$\mathrm{Aa} \mathrm{Aa}$ \\ HUMANISTAS \\ SEM SERIFAS HUMANISTAS \\ Aa Aa \\ TRANSICIONAIS

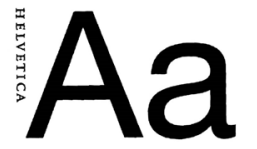 \\ SEM SERIFAS TRANSICIONAIS}

Figura 2: Exemplo das categorias citadas por Lupton. Fonte: Lupton, 2006, p.42.

Figura 3: Exemplo de tipografias da categoria display. Fonte: O'GRADY, 2008, p.124.

Após esses breves apontamentos acerca do Design Editorial, a seguir serão apresentadas cada escolha projetual feita para o desenvolvimento do projeto gráfico pretendido por esta pesquisa, mostrando de forma aplicada cada um desses conceitos explicados anteriormente e alguns outros, além da metodologia projetual estabelecida.

\section{PROJETO DO LIVRO}

Aqui são abordadas as escolhas projetuais, as quais foram desenvolvidas usando como base os conceitos editoriais explicados anteriormente e empregadas na criação do projeto gráfico resultante desta pesquisa. Além da metodologia usada para acessar as memórias familiares como forma de reunir as receitas que compõem o livro.

Como abordado anteriormente, a prática projetual desta pesquisa configura-se como um livro de receitas da avó da autora e é restrito somente ao âmbito de sua família, pois não faria sentido para eles comercializar momentos de tamanha intimidade. Entretanto, não será um objeto único, como um livro de artista, nem de caráter artesanal. Ele foi proje- 
tado para ser reprodutível, dando a chance de cada familiar que desejar, possuir uma cópia.

Para selecionar quais receitas deveriam fazer parte deste livro foi feita uma amostragem de caráter exploratório por acessibilidade (GIL, 2008, p.94) com cinco membros da família. Estes foram escolhidos por serem os parentes mais próximos da autora e possuírem maior ligação com sua avó, personagem principal deste livro. As perguntas realizadas foram: "Quais comidas feitas pela avó, sejam simples ou elaboradas, não podem faltar nessa lista?", "Quais motivos te levaram a escolhê-las?" e "O que essas receitas te fazem lembrar?". Houve o cuidado de que ninguém tomasse conhecimento das respostas dos demais parentes para que não fossem influenciados, porém, mesmo assim, as escolhas individuais foram muito semelhantes entre si. Apesar dos poucos membros entrevistados, a lista de receitas foi muito maior do que o imaginado. Infelizmente, não foi possível incluir o grande número de receitas escolhidas pela família neste trabalho por não haver tempo hábil de prepará-las. Dessa forma, a seleção foi feita pela autora junto de sua avó, escolhendo as receitas mais significativas para serem reproduzidas e inseridas no livro. Nesse processo, sua avó identificou receitas que não constavam na lista, porém julgava importantes, dessa maneira, algumas foram retiradas, enquanto outras, acrescentadas, até chegar nesta listagem final (Figura 4).

\section{Receitas selecionadas}
1. Bolo do vô
2. Bolo de maçã
3. Broa de milho
4. Bolo de figo
5. Cuca de goiabada
6. Ambrosia
7. Torta de bolachinha
8. Ovos nevados
9. Bombom de morango
10. Ovos moles
11. Torta de amendoim
12. Rei Alberto
13. Pudim de laranja colonial
14. Pudim de leite condensado
15. Quindim
16. Pudim de claras
17. Pudim de queijo
18. Sorvete de latinha
19. Pudim de batata

Figura 4: Listagem final com as receitas selecionadas para compor o livro. Fonte: Elaborada pela autora. 
Para iniciar de fato a construção deste livro a autora junto de sua avó e de sua mãe, analisaram a lista de receitas e montaram um cronograma especificando em quais dias das semanas seguintes cada receita seria feita. Seguiu-se uma lógica de levar em consideração as bases de preparação de cada uma, por exemplo: todas as receitas que levassem claras de ovos como ingrediente principal seriam feitas no mesmo dia, enquanto as que levassem as gemas restantes, seriam feitas nos dias seguintes.

Antes de preparar a primeira receita, realizou-se uma busca por referências no site Pinterest, onde encontrou-se imagens que ilustraram as intenções projetuais da estética gráfica do livro. Essa etapa foi essencial, pois para fotografar os pratos prontos, o ideal seria já ter um conceito estabelecido. Diante disso, chegou-se ao resultado deste moodboard (Figura 5) com referências tanto de diagramação, quanto de fotografias.

Nas fotografias, mais importante do que registrar somente os pratos prontos, era essencial que a "memorabilia" (CARDOSO, 2012) da avó se fizesse presente como forma de despertar mais ainda as memórias da família. Para tanto, além de montar e apresentar os pratos nas louças colecionadas por ela ao longo dos anos, usou-se para compor os cenários itens que são característicos de sua casa, como as mesas de madeira, a bancada de granito, o chão de mármore, as bandejas e as flores usadas na decoração. Por não ter habilidades na área da fotografia, a autora contou com a ajuda de uma amiga e colega de curso, Corina Minsky. Dessa forma, as receitas eram preparadas durante o dia, para que a noite fossem fotografadas com a estética desejada.

Após o primeiro dia de execução das receitas e fotografias, começou-se os testes do projeto gráfico em si. A primeira ideia foi a de fazer um livro no formato de um retângulo vertical, pois seguindo os conceitos de Hendel (2006), esse seria o formato mais tradicional e familiar à maioria das pessoas. Entretanto, ao fazer os primeiros testes, percebeu-se que alguns pratos ficavam melhor enquadrados quando fotografados na vertical, 

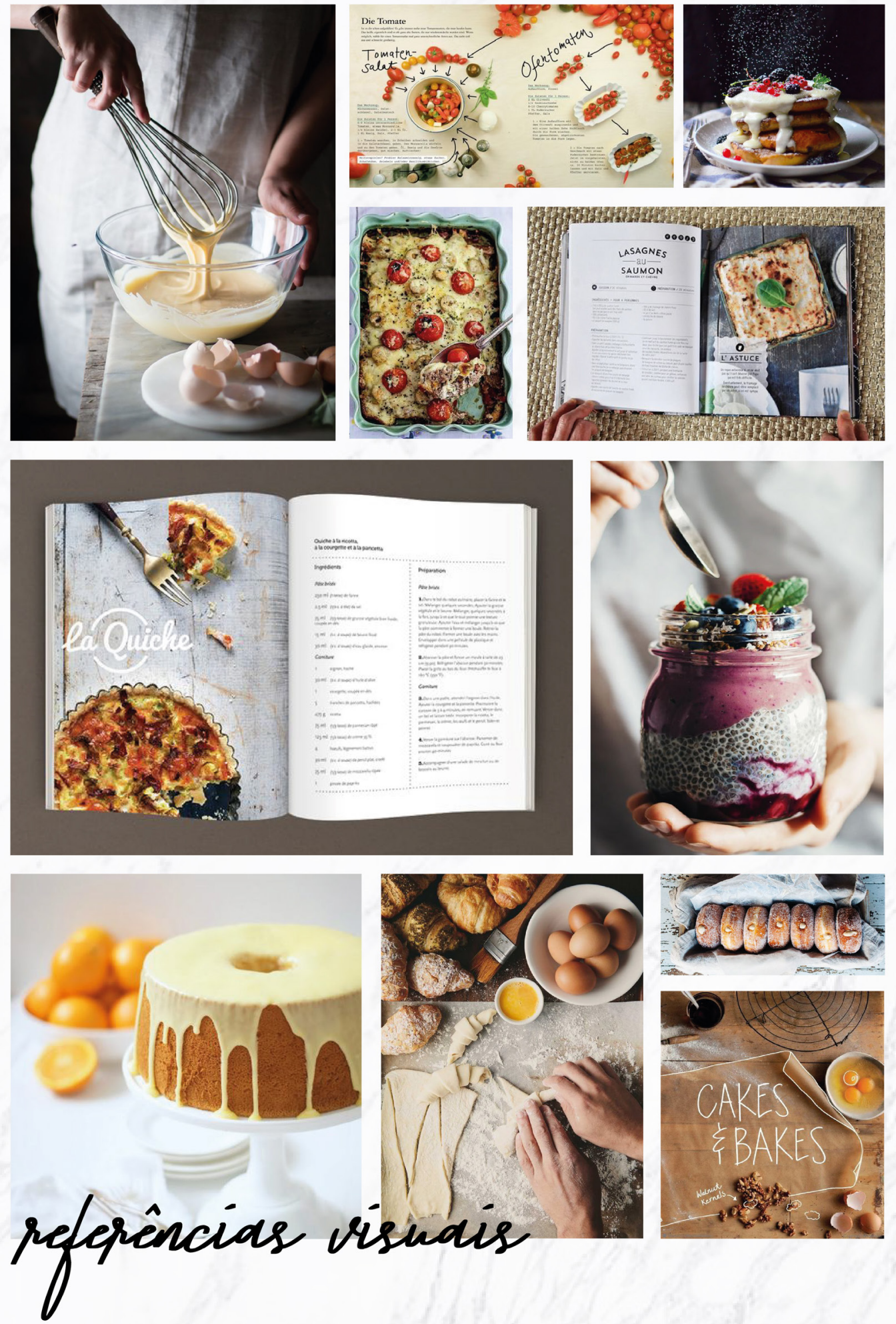

Figura 5: Moodboard com referências visuais. Fonte: https://goo.gl/WKzWLC

enquanto outros, na horizontal. Diante disso, optou-se pelo quadrado como formato do livro, pois assim as fotografias poderiam ser adequadas nas margens, sangrando tanto para cima e para baixo, quanto para os lados, dependendo de sua 
necessidade (Figuras 6 e 7). Pensando nos tamanhos de papéis mais facilmente encontrados no mercado, as dimensões do livro foram estabelecidas como $20 \times 20 \mathrm{~cm}$, pois considerando o livro aberto como $40 \mathrm{~cm}$ de largura somando as margens deixadas pela impressora, é o tamanho ideal para a impressão em papel A3, cujas medidas são 42×29,7 cm (Figura 8), o que facilitaria a reprodução do projeto em qualquer gráfica expressa, de acordo com a disponibilidade dos membros da família interessados em produzir uma cópia.
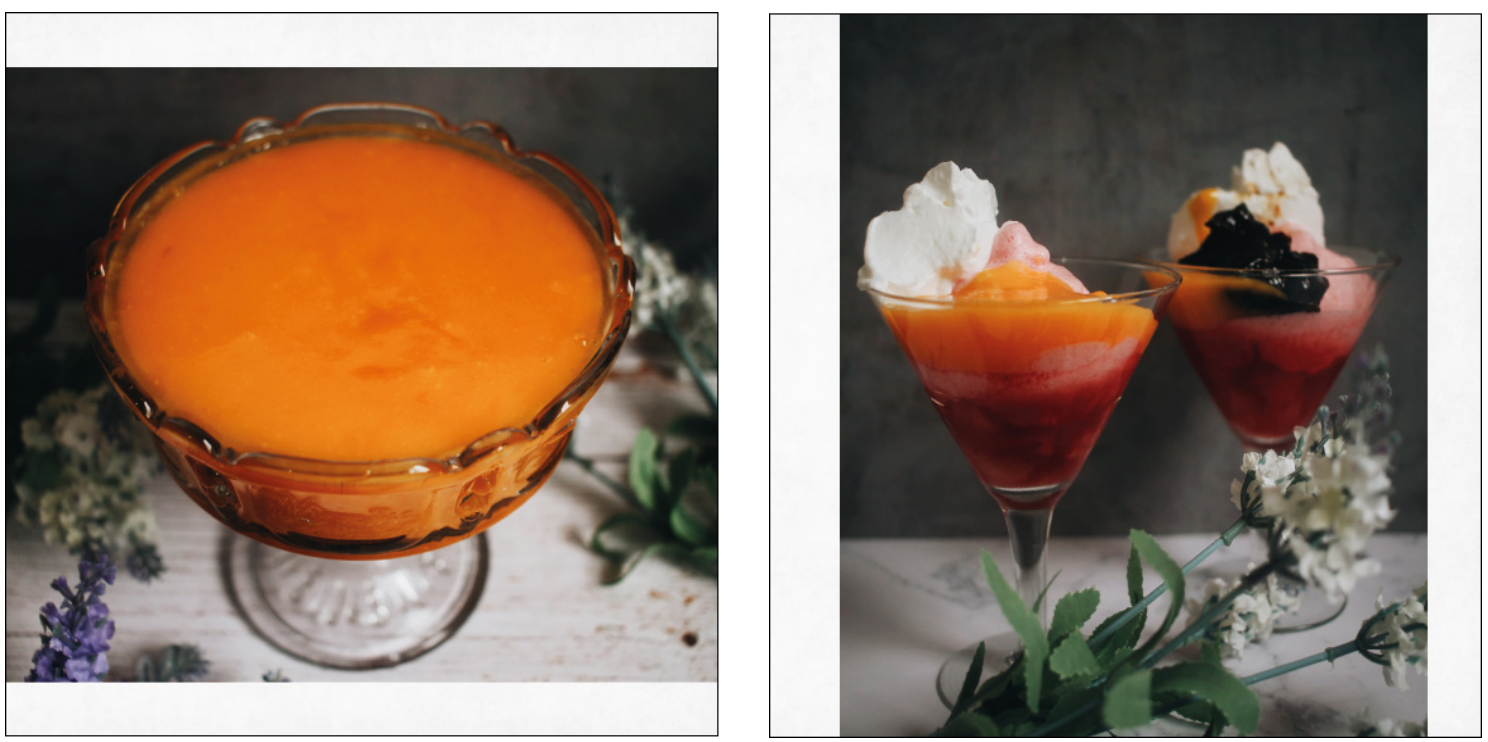

Juntamente com a definição do formato do livro, se deu a construção do grid que iria guiar a diagramação de todo projeto gráfico. Ao realizar a pesquisa de referências visuais citada anteriormente, percebeu-se que grande parte dos livros deste segmento possuem um grid de duas colunas (Figura 9), acomodando a lista de ingredientes em uma e o modo de preparo em outra.

Este mesmo raciocínio acabou sendo seguido, porém um grid de colunas não seria suficiente para encaixar os elementos que iriam ser trazidos no projeto. Então, para atender o grau de complexidade dos elementos a serem inseridos na
Figura 6 (esquerda): Exemplo de prato melhor enquadrado na horizontal, sangrando nas laterais. Fonte: Corina Minsky, acervo da autora.

Figura 7 (direita): Exemplo de prato melhor enquadrado na vertical, sangrando em cima e embaixo. Fonte: Corina Minsky, acervo da autora. 


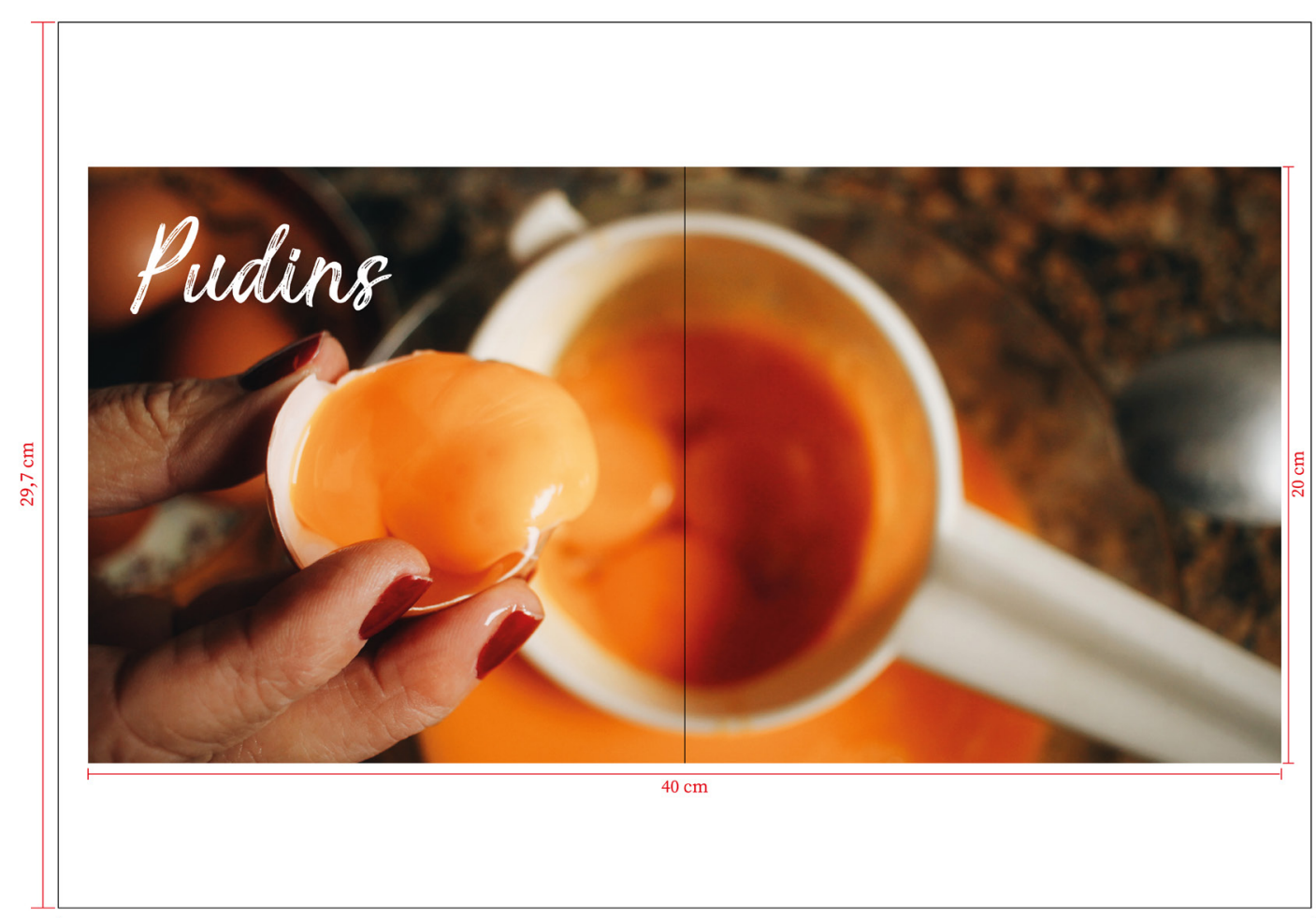

$42 \mathrm{~cm}$
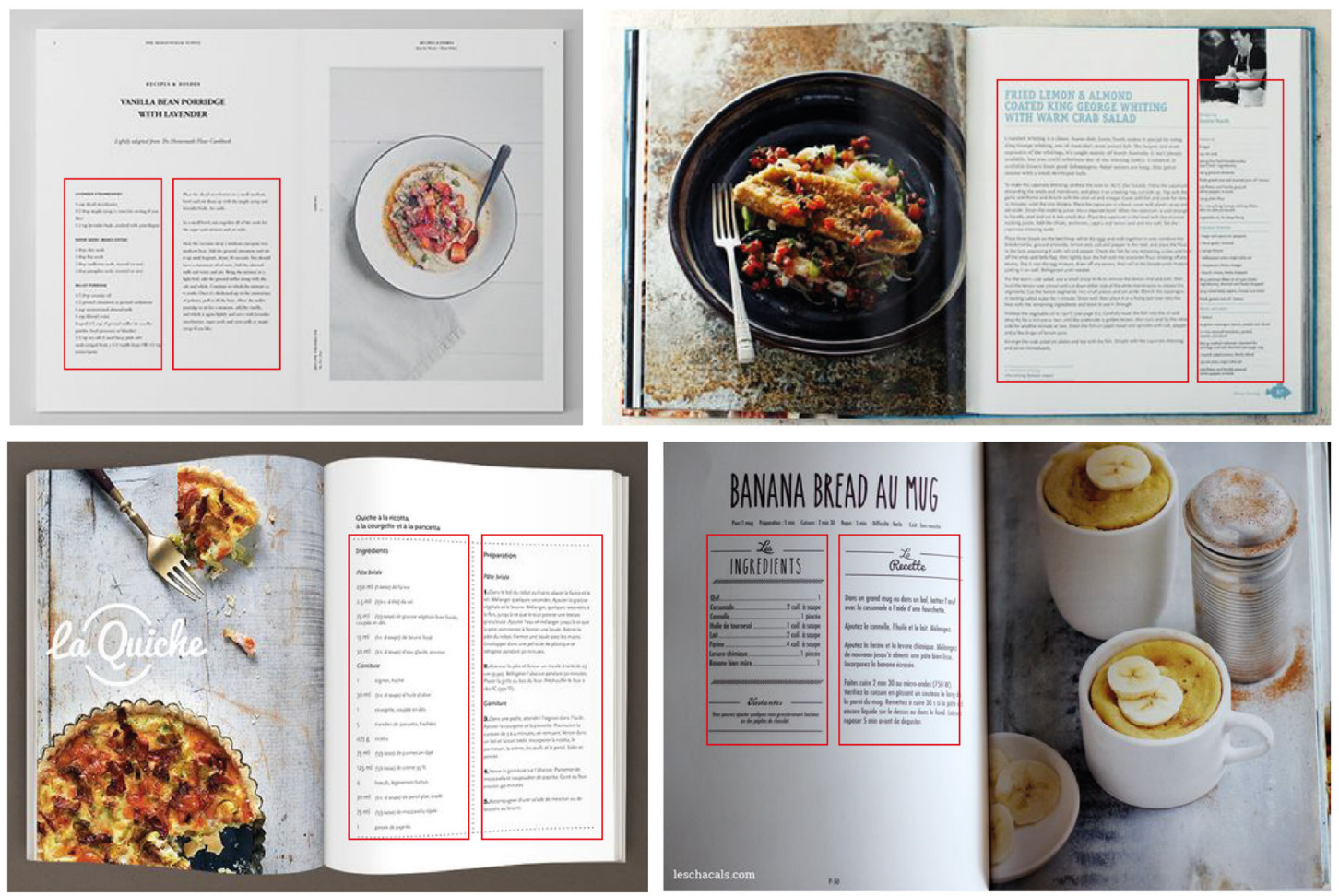

Figura 8: Relação do papel A3 com o tamanho do livro. Fonte: Elaborado pela autora.

Figura 9: Exemplos de livros de receitas de duas colunas. Fonte: $h$ ttps://goo.gl/WKzWLC 
obra, criou-se um grid modular. Para Samara (2007, p.28), “o grau de controle dentro do grid depende do tamanho dos módulos. Os menores oferecem mais flexibilidade e mais precisão, mas um excesso de subdivisões pode gerar confusão ou redundância". Por isso, a página foi dividida em sete módulos horizontais e verticais, para que eles não ficassem nem muito grandes, nem muito pequenos, proporcionando o controle ideal. Após realizar essa divisão, foram criadas as "zonas espaciais", que segundo o mesmo autor, são a junção dos pequenos módulos em áreas que recebem funções específicas. Ficaram definidas então uma zona para o título, outra para os pictogramas dos detalhes da receita, outra para os ingredientes e por fim, para o modo de preparo (Figura 10).

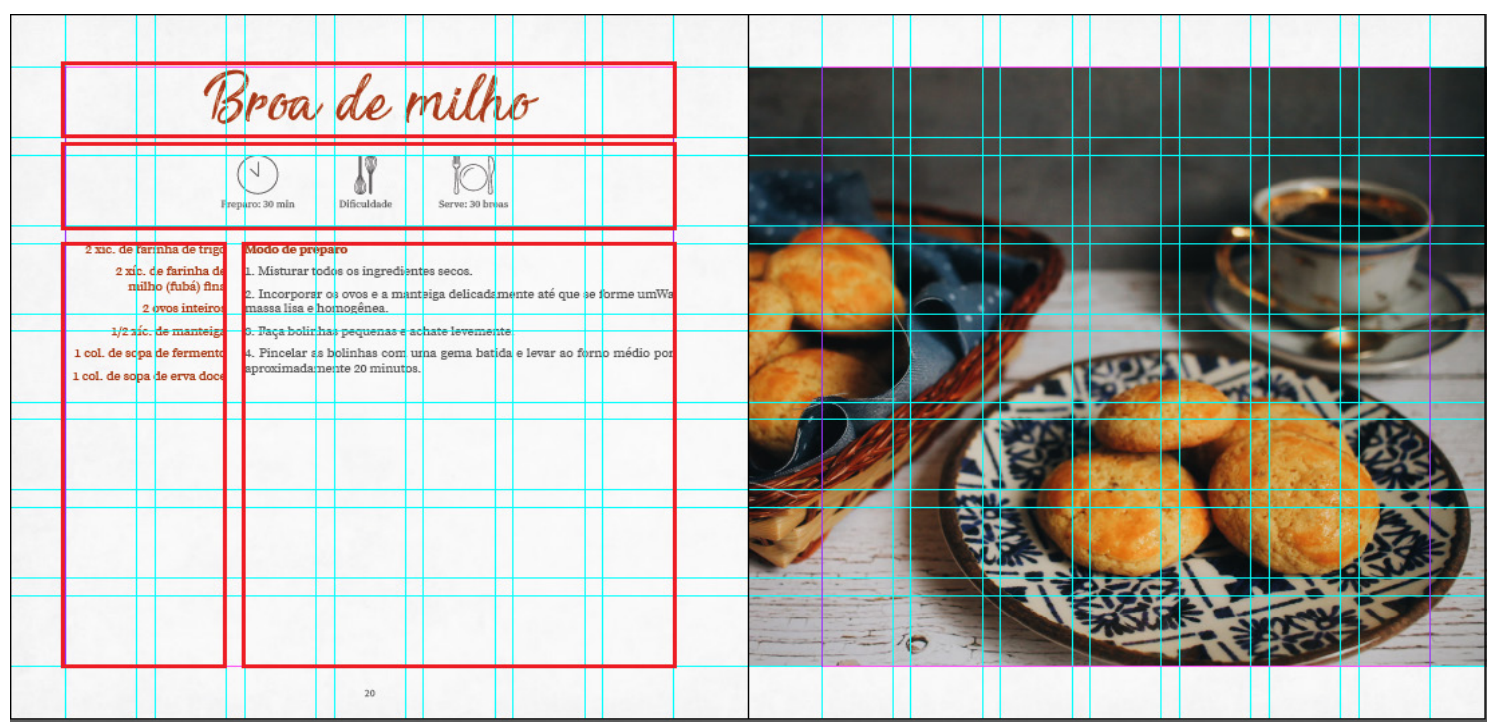

Além do título, destacou-se também o tempo de preparo, a dificuldade de cada receita e o rendimento (Figura 11). Apesar desses itens nem sempre serem mencionados, julgou-se de extrema importância salientá-los, pois assim, as pessoas que nunca tiveram a chance de cozinhar determinada receita, não saberem quanto tempo precisam ter disponível ou se a sobremesa servirá a todos da família, podem descobrir essas informações de forma rápida.
Figura 10: Exemplo de aplicação do grid. Fonte: Elaborado pela autora. 


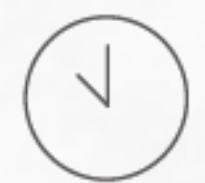

Preparo: $30 \mathrm{~min}$

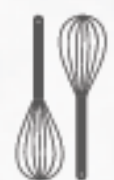

Dificuldade

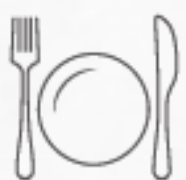

Serve: 30 broas
Figura 11: Pictogramas usados para dar destaque aos detalhes da receita. Fonte: Elaborado pela autora.

No sumário (Figura 12) manteve-se o grid modular, porém dividiu-se em duas zonas, uma para os nomes das seções e outra para as receitas e suas respectivas páginas. A fotografia da página direita é sangrada até a primeira coluna de módulos da página esquerda, tornando o conjunto mais equilibrado visualmente.
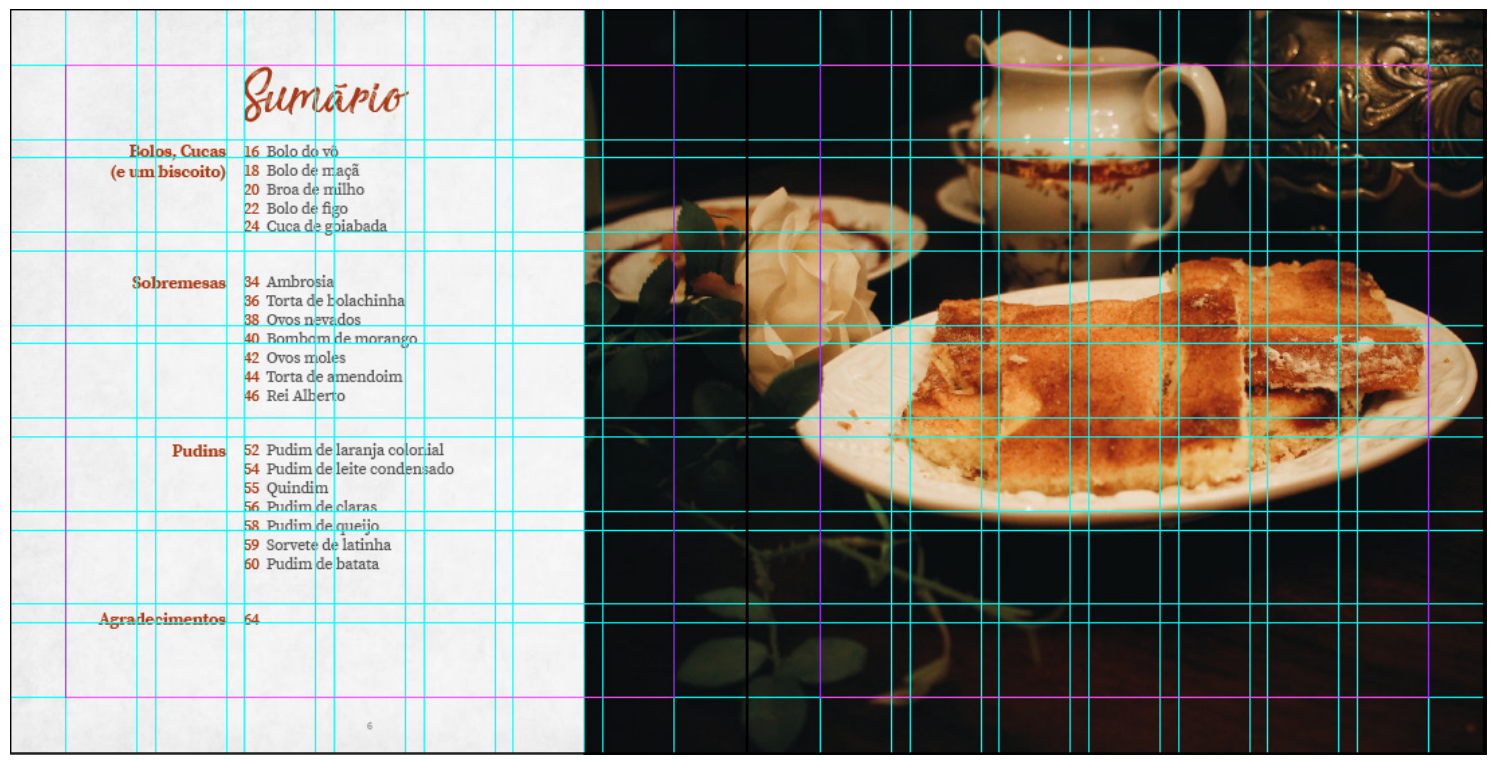

Figura 12: Sumário do livro. Fonte: Elaborado pela autora.

Com o intuito de aproximar o leitor de sua avó e tornar o passo a passo mais fiel, em algumas receitas a autora criou um box de informação onde apresentou a "Dica de vó!" (Figura 13). Nele são apresentados passos extras, substitui- 
ções possíveis de ingredientes, explicação de alguma etapa importante ou qualquer outro conselho que ela tenha dado no meio da preparação da receita. Esse box não possui variação de tamanho nem de cor, se encontra sempre na mesma posição, alinhado na base inferior da página sangrando nas margens e ocupando um módulo de altura e sete de largura.

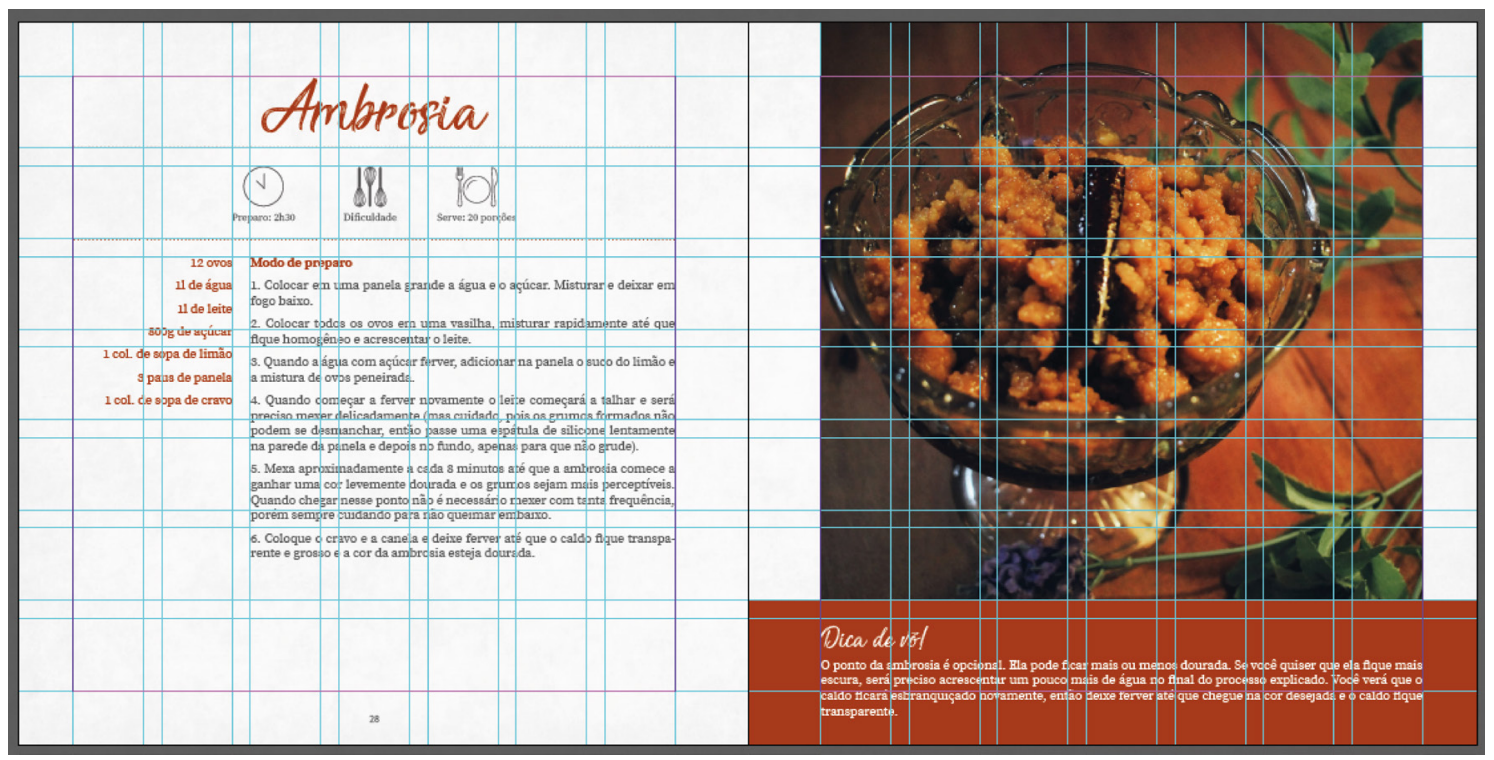

Para as escolhas tipográficas, primeiro buscou-se encontrar a tipografia que seria usada para os títulos. Baseando-se nos conceitos abordados na seção anterior, era desejado que esta fosse no estilo display (O'GRADY, 2008) para trazer a ideia de caligrafia, pois traz o "feito à mão" do cozinhar e o escrever as receitas a próprio punho. Para isso, realizou-se uma pesquisa em sites da internet, onde foram encontradas algumas tipografias que se encaixavam nessa descrição, até chegar à escolhida. Para o texto, decidiu-se fazer o uso de uma tipografia transicional com serifa (LUPTON, 2006), pois além de aumentar a legibilidade do texto, tornando sua leitura mais fluida e leve, ainda contribui no aspecto clássico e tradicional almejado no projeto. As duas tipografias determinadas foram, então, a "SensationsandQualities" para os títulos, que
Figura 13: Exemplo de box de informação "Dica de vó!". Fonte: Elaborado pela autora. 
é usado no tamanho de corpo 71 pt, sempre centralizados em relação às margens; e a família "SourceSerif Pro" para os textos no tamanho de corpo 10 pt (Figura 14).
ABCDEFGHIJKLMNOPQRSTUVWXYZ

abcdefghijklmnopqrstuvwxyz

Source Serif Pro Regular

ABCDEFGHIJKLMNOPQRSTUVWXYZ

abcdefghijklmnopqrstuvwxyz

Source Serif Pro SemiBold

ABCDEFGHIJKLMNOPQRSTUVWXYZ

abcdefghijklmnopqrstuvwxyz

Source Serif Pro Bold
Figura 14: Famílias tipográficas escolhidas. Fonte: Elaborado pela autora

Lupton (2008, p.53), explica que "o designer usa texturas para estabelecer uma atmosfera, reforçar um ponto de vista ou expressar uma sensação de presença física". Diante disso, para ambientar ainda mais o projeto como algo de família e remeter a cadernos de receitas antigos, fez-se o uso de texturas no decorrer dele. Para a folha de guarda (Figura 15), usou-se a imagem de uma página de papel envelhecida e dobrada com a sobreposição de uma receita escrita à mão pela avó da autora, a qual foi digitalizada para essa aplicação. Em todas as outras páginas também foi aplicado uma leve textura de papel acinzentado ao fundo (Figura 16). Além da textura da própria tipografia usada para os títulos (Figura 16), que como já explicado anteriormente, traz a ideia de escrito à mão.

Ainda para contribuir com a ambientação do projeto, Lupton (2008, p.71) acrescenta que "a cor pode exprimir uma atmosfera, descrever uma realidade ou codificar uma informação". Com isso, a paleta de cores (Figura 17) escolhida foi extraída do ambiente em que as receitas foram fotografadas, no caso, a casa da avó da autora. As mesas de madeira, a luz fraca e amarelada, serviram para deixar as fotografias com o caráter exato daquela casa, que possui um significado especial para os 
Figura 15: Exemplo de textura aplicada na folha de guarda. Fonte: Elaborado pela autora.

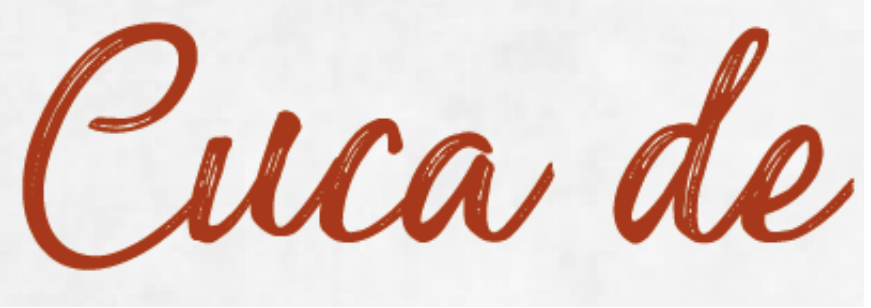

Figura 16: Exemplo de textura aplicado nas folhas e da tipografia. Fonte: Elaborado pela autora.

pretensos leitores do livro. Por conta disso, escolheu-se continuar com os tons terrosos para os elementos de destaque, que são os títulos das receitas, as linhas que separam os pictogramas, as lista de ingredientes, e o box de informação, mantendo um esquema de cores análogas em todo o livro. Para decidir a cor, foi usado a ferramenta de conta-gotas do software de edição de imagens em uma das fotos tiradas até encontrar a que melhor se adequasse. Para os outros elementos e texto, usou-se o preto $80 \%$, de forma que a diferença visual ficasse mais harmoniosa e menos carregada do que com o preto $100 \%$.

Para a capa do livro (Figura 18), optou-se por uma fotografia com a mesma estética das páginas internas e que pudesse ser usada de forma contínua como capa e contracapa. Ela foi escolhida por trazer a xícara de café e a cuca partida em cima da mesa, despertando lembranças dos cafés da tarde na casa da vó. O nome da avó da autora desta pesquisa foi usado como escritora do livro, pois, apesar de organizadas e reescritas pela pesquisadora, as receitas são originalmente dela. 0 nome "Doce de vó" foi escolhido por levantar certa ambiguidade, pois ele pode ser interpretado como sendo sobre a doçura na personalidade da avó, ou sobre os doces feitos por ela. 

C 24
M 86
Y 97
K 19

Figura 17: Paleta de cores $e$ suas especificações. Fonte: Elaborado pela autora.

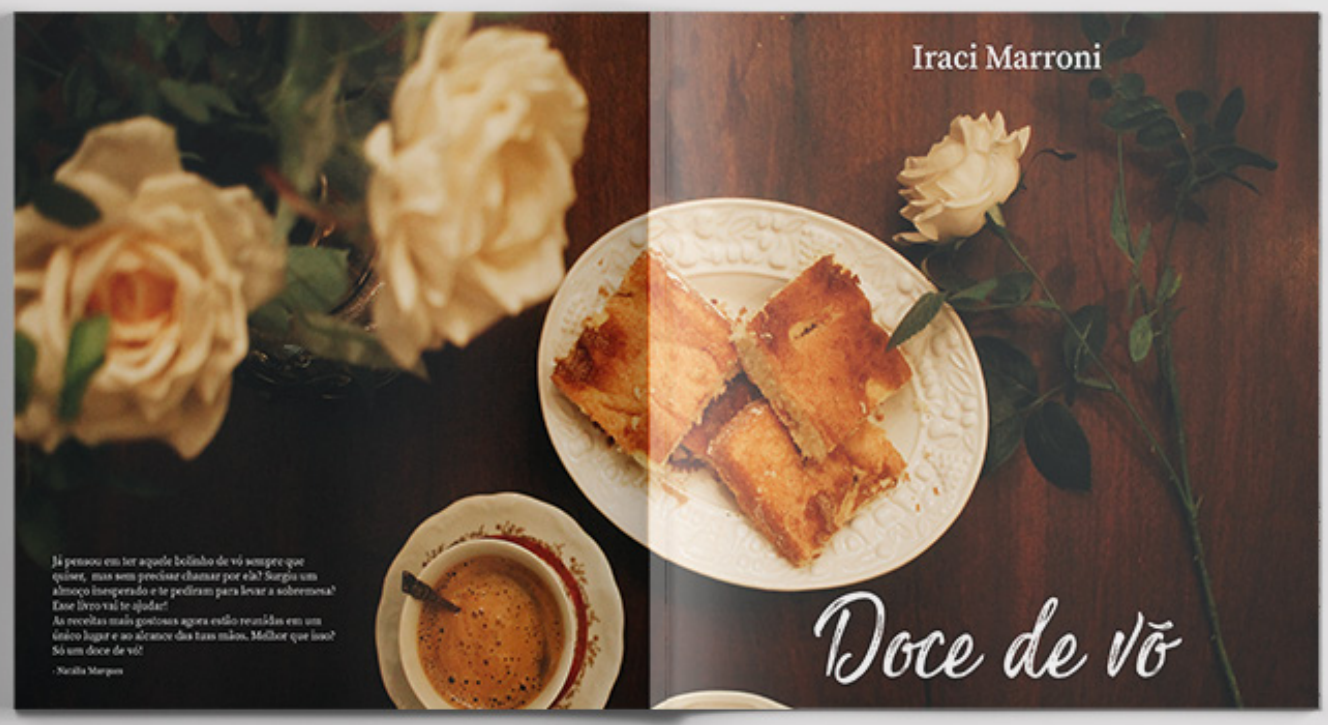

Figura 18: Imagem da capa do livro. Fonte: Elaborado pela autora.

Essas foram, então, as escolhas projetuais feitas para a construção da prática projetual desta pesquisa. Por ser um projeto destinado à sua família, a autora quis que a diagramação do livro ficasse simples e direta, de forma que desde as pessoas mais velhas, quanto as pessoas mais novas pudessem compreender com facilidade a descrição das receitas, com as fotografias servindo de apoio para ilustrar o resultado final. 


\section{CONSIDERAÇÕES FINAIS}

Como forma de encerramento, é necessário retomar os objetivos expostos no início do texto, os quais serviram de guia para a elaboração desta pesquisa e entender de que maneira o estudo de cada seção foi útil para a prática projetual.

Estudar os elementos editoriais necessários para a criação do projeto gráfico de um livro, proporcionou que fosse resolvido o objetivo geral, com o desenvolvimento de um livro que servisse como suporte das lembranças familiares. Esses conceitos estão diretamente ligados com os temas abordados na seção de design e memória, pois o livro atua como um artefato que cristaliza e transmite as tradições e memórias através do tempo, sendo um elo entre as gerações.

Entre os objetivos específicos alcançados nessa pesquisa, está a coleta documental realizada nas "reservas técnicas" (COSTA, 1995) da avó da autora e entrevista com os membros mais próximos da sua família. Essa serviu para elencar as receitas que integrariam o livro. Outro objetivo específico alcançado foi a execução de algumas receitas selecionadas ao lado da avó, onde pode ser descrito o passo a passo conforme ela as cozinhava.

Esse trabalho foi de extrema importância emocional para a família, pois com ele, a avó sentiu-se homenageada e valorizada. Fez também com que a família se reunisse para comer os doces feitos, criando novos bons momentos que serão lembrados por todos. Além, é claro, desse novo artefato que agora também faz parte da identidade familiar.

Assim, considera-se atingidos os objetivos propostos e ressalta-se a relevância deste tipo de prática projetual, especialmente em tempos onde a personalização de produtos de design parece receber uma (re)valorização muito pertinente. 


\section{REFERÊNCIAS BIBLIOGRÁFICAS}

BARROS, Myriam de. Memória e Família. In: Estudos

Históricos. Rio de Janeiro, v. 2, n. 3, p. 29-42, 1989.

CARDOSO, Rafael. Design para um mundo

complexo. São Paulo: Cosac Naify, 2012.

CHAUI, Marilena. Convite à filosofia.

São Paulo: Editora Átiva, 2000.

COSTA, Maria C. O Objeto, o Colecionador e o Museu.

Revista Imaginário, São Paulo, n.2, p. 37-45, jan. 1995.

DEMETERCO, Solange Menezes da Silva. Sabor e

saber: Livros de cozinha, arte culinária e hábitos

alimentares. Curitiba: 1902 - 1950. Tese de

Doutorado, Universidade Federal do Paraná, 2003.

Dicionário Michaelis. Disponível em <http://michaelis. uol.com.br/moderno-portugues/busca/portugues-

brasileiro/livro/>. Acesso em 25 de fevereiro de 2018.

GIL, A. C. Como elaborar projetos de

pesquisa. São Paulo: Atlas, 2002. 4. ed. Métodos e Técnicas de Pesquisa

Social. São Paulo: Atlas, 2008. 6. ed.

HALBWACHS, Maurice. A memória coletiva.

São paulo: Biblioteca Vértice, 1990.

HASLAM, Andrew. O livro e o designer II: como criar

e produzir livros. São Paulo: Edições Rosari, 2010.

HENDEL, Richard. O Design do livro. São

Paulo: Ateliê Editorial, 2006.

LIMA, Paula Garcia. Estudo da memória e do conceito de design através das peças gráficas e fotografias do Parque Souza Soares (Pelotas, 1900-1930). Dissertação de Mestrado, Universidade Federal de Pelotas, Pelotas, 2010. 
Memórias do feminino através dos

reclames dos Almanachs de Pelotas (1913 - 1935). Tese

(Doutorado em Memória Social e Patrimônio Cultural).

Universidade Federal de Pelotas, Pelotas, 2015.

LUPTON, Ellen. Pensar com Tipos: para designers, escritores,

editores e estudantes. São Paulo: Cosac Naify, 2006.

Novos fundamentos do design: Ellen

Lupton, Jennifer Cole Phillips. São Paulo, Cosac Naify, 2008.

O'GRADY, Jenn.The Information Design

Handbook. HOW Books, 2008.

POLIDORI, Estela. Memória e design: catálogo da

restauração do Casarão $\mathbf{n}^{\circ} 08$ de Pelotas. Trabalho

de Conclusão de Curso (Graduação em Design

Gráfico). Universidade Federal de Pelotas, 2014.

SAMARA, Timothy. Grid: construção e

desconstrução. São Paulo: Cosac Naify, 2007

SEHN, Thaís. O livro como objeto de desejo. Trabalho

de Conclusão de Curso (Graduação em Design

Gráfico), Universidade Federal de Pelotas, 2009. 